\title{
Some New Nickel 1,2-Dichalcogenolene Complexes as Single-component Semiconductors
}

\author{
George C. Papavassiliou ${ }^{a}$, George C. Anyfantis ${ }^{a}$, Barry R. Steele ${ }^{b}$, Aris Terzis ${ }^{c}$, \\ Catherine P. Raptopoulou ${ }^{\mathrm{c}}$, George Tatakis ${ }^{\mathrm{d}}$, George Chaidogiannos ${ }^{\mathrm{d}}$, Nikos Glezos ${ }^{\mathrm{d}}$, \\ Yufeng Weng ${ }^{\mathrm{e}}$, Harukazu Yoshino ${ }^{\mathrm{e}}$, and Keizo Murata ${ }^{\mathrm{e}}$ \\ a Theoretical and Physical Chemistry Institute, National Hellenic Research Foundation, 48, \\ Vassileos Constantinou Ave., Athens 116-35, Greece \\ ${ }^{b}$ Organic Chemistry Institute, National Hellenic Research Foundation, Athens 116-35, Greece \\ ${ }^{c}$ Institute of Materials Science, NCSR, Demokritos, Athens 153-10, Greece \\ ${ }^{\mathrm{d}}$ Institute of Microelectronics, NCSR, Demokritos, Athens 153-10, Greece \\ ${ }^{\mathrm{e}}$ Graduate School of Science, Osaka City University, Osaka 558-8585, Japan \\ Reprint requests to Prof. G. C. Papavassiliou. Fax (30210) 7273794. E-mail: pseria@eie.gr
}

Z. Naturforsch. 2007, 62b, 679-684; received November 29, 2006

The complexes $\mathrm{Ni}(\mathrm{dmeds})(\mathrm{dmit}), \mathrm{Ni}(\mathrm{dmedt})(\mathrm{dmit}), \mathrm{Ni}(\mathrm{dpedt})(\mathrm{dsit}), \mathrm{Ni}(\mathrm{dpedt})(\mathrm{dmit})$, and $\mathrm{Ni}(\mathrm{dcdt})(\mathrm{dmit})$ (where dmeds is dimethylethylenediselenolate, dmedt is dimethylethylenedithiolate, dpedt is diphenylethylenedithiolate, dcdt is 1,2-bis-decylsulfanyl-ethene-1,2-dithiolate, dmit is 1,3-dithiol-2-thione-4,5-dithiolate, and dsit is 1,3-dithiol-2-thione-4,5-diselenolate) were prepared and characterized. The new complexes exhibit semiconducting behavior, with band gap values around $0.8 \mathrm{eV}$.

Key words: Metal 1,2-Dichalcogenolenes, Single-component Semiconductors

\section{Introduction}

During the last five years a number of singlecomponent (neutral) metal 1,2-dichalcogenolenes have been prepared and studied in our laboratories and/or in a collaboration with others [1-6]. Some unsymmetrical complexes were found to be stable in air and soluble in organic solvents. They exhibit strong nonlinear optical (NLO) properties [5,6] and/or show semiconducting behavior under the conditions of field-effect transistors (FETs) [3,4].

In this paper, the preparation and characterization of $\mathrm{Ni}(\mathrm{dmeds})(\mathrm{dmit}), \mathrm{Ni}(\mathrm{dmedt})(\mathrm{dmit}), \mathrm{Ni}$ (dpedt)(dsit), $\mathrm{Ni}$ (dpedt)(dmit) and $\mathrm{Ni}(\mathrm{dcdt})(\mathrm{dmit})$ are described (where dmeds is dimethylethylenediselenolate [7,8], dmedt is dimethylethylenedithiolate [7], dpedt is diphenylethylenedithiolate [7], dcdt is 1,2-bis-decylsulfanyl-ethene-1,2-dithiolate [9], dmit is 1,3-dithiol2-thione-4,5-dithiolate $[9,10]$ and dsit is 1,3-dithiol-2thione-4,5-diselenolate $[9,10])$. These new unsymmetrical (mixed ligand) complexes were prepared by the cross-coupling method [2] according to the procedures of Scheme 1. The starting materials $\mathbf{1}-\mathbf{5}$ were prepared by methods reported in $[11-17]$ (see also $[7,8,10]$ ). The required unsymmetrical complexes were separated from the corresponding symmetrical byproducts by liquid column chromatography. For one of them, $\mathrm{Ni}(\mathrm{dmeds})(\mathrm{dmit})$, the crystal structure determination is reported. All the complexes exhibit semiconducting behavior similar to that observed in $\mathrm{Ni}(\mathrm{pddt})(\mathrm{dmio})$ and $\mathrm{Ni}(\mathrm{pddt}$ (dmit), where pddt is 6,7-dihydro-5H-1,4dithiepin-2,3-dithiolate and dmio is 1,3-dithiol-2-one4,5-dithiolate [3].

\section{Results and Discussion}

From equimolar amounts of starting materials the unsymmetrical complexes $\mathrm{Ni}(\mathrm{dmeds})(\mathrm{dmit})$, $\mathrm{Ni}(\mathrm{dmedt})(\mathrm{dmit}), \mathrm{Ni}$ (dpedt)(dsit), Ni(dpedt)(dmit) and $\mathrm{Ni}(\mathrm{dcdt})(\mathrm{dmit})$ were obtained in $0.9,2.4,2.5,21.0$, and $0.8 \%$ yields, respectively. The unsymmetrical complexes containing the ligands dmit, dsit (or dmio) are expected to have redox-potential values higher than those of the corresponding symmetrical ones, $\mathrm{Ni}(\mathrm{dmedt})_{2}, \mathrm{Ni}(\mathrm{dmeds})_{2}, \mathrm{Ni}(\mathrm{dpedt})_{2}$ and $\mathrm{Ni}(\mathrm{dcdt})_{2}$, i. e., they are expected to be stable in air (see $[3,4,7,9,10,18,19])$. The new complexes were found to be soluble in $\mathrm{CS}_{2}$ and some other organic solvents. From the solutions single crystals and/or thin deposits of complexes on quartz and $\mathrm{Si}-\mathrm{SiO}_{2}$ substrates were obtained. Solutions and thin deposits were found spectroscopically to be stable in air, as it was expected 

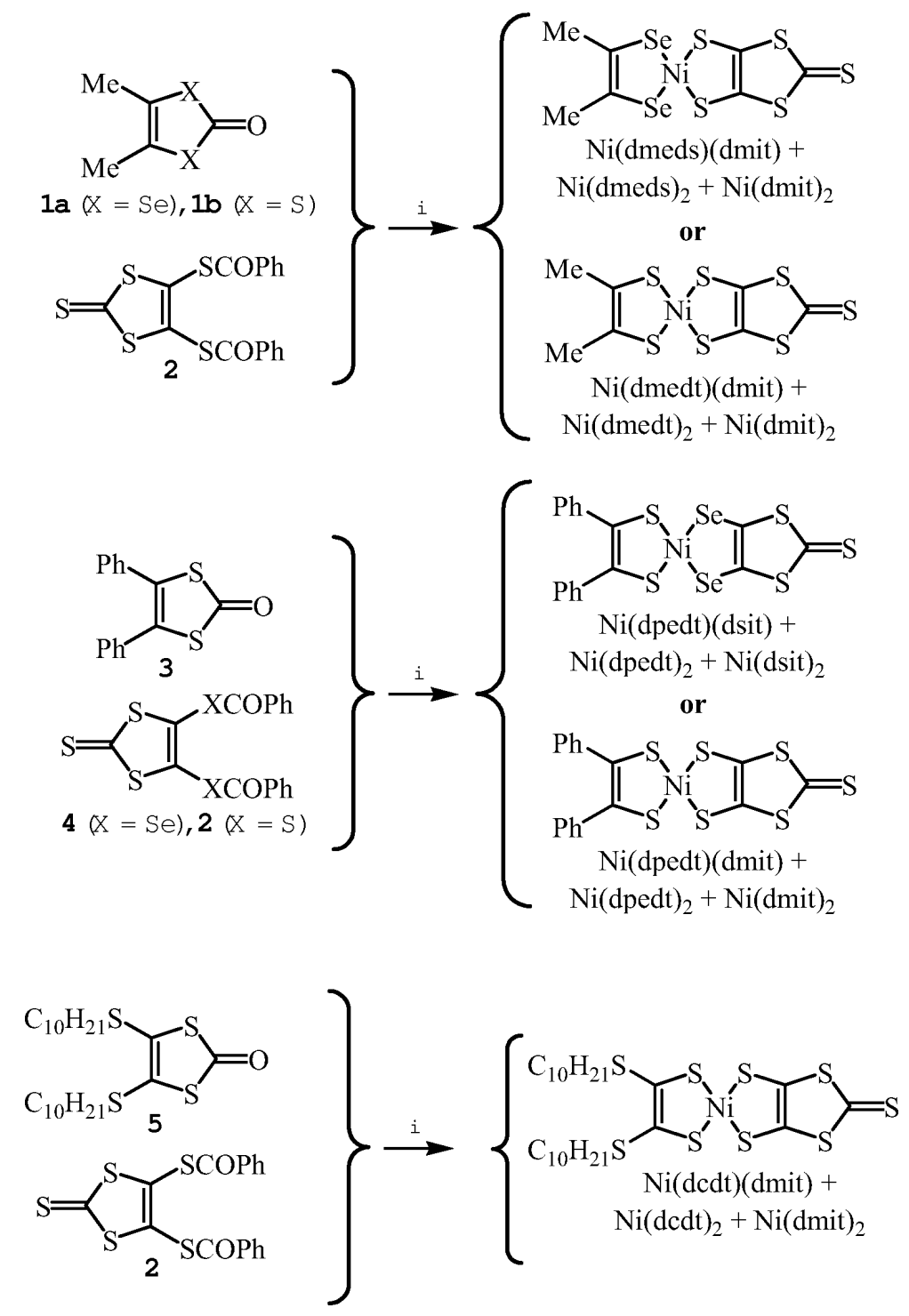

Scheme 1. $\mathrm{i}=1: \mathrm{NaOMe}$ in $\mathrm{MeOH}$, $\mathrm{i}=2: \mathrm{NiCl}_{2}$ in $\mathrm{MeOH}, \mathrm{i}=3$ : aq. $\mathrm{HCl}$ $(35 \%)$ in air.

from the electrochemical data, and moreover stable in light for a long time. By treatment with $\mathrm{NaBH}_{4}$ in acetone and in the presence of $\mathrm{Bu}_{4} \mathrm{~N}^{+}$the anionic species can be obtained.

Single crystals of $\mathrm{Ni}(\mathrm{dmeds})(\mathrm{dmit})$ had a rectangular shape and were found to be suitable for $\mathrm{X}$-ray crystal structure determination. The complex $\mathrm{Ni}$ (dmeds)(dmit) crystallizes in the triclinic space group $P \overline{1}$. Crystal and refinement data are summarized in Table 1. Fig. 1 shows the molecular structure and Fig. 2 shows a partially labelled plot of the complex. The structure consists of centrosymmetric dimers [20] with the inversion center sitting on the center of the $\mathrm{Ni}_{2} \mathrm{Se}_{2}$ core. The closest $\mathrm{Ni} \cdot \mathrm{S}$ and $\mathrm{Ni} \cdot \mathrm{Se}$ bond lengths in the coordination sphere are ca. 2.2 and $2.3 \AA$, respectively, while the longer $\mathrm{Ni} \cdots \mathrm{Se}$ bond $(2.56 \AA)$ is responsible for the formation of the dimers. The closest intramolecular $\mathrm{Ni} \cdot \mathrm{Ni}$ distance is ca. $3.06 \AA$. It was found that the largest surface of the rectangular crystals is almost parallel to the crystallographic $a b$ plane. There are S $\cdots \mathrm{S}$ and $\mathrm{S} \cdots \mathrm{Se}$ intermolecular contacts of 3.594 and $3.610 \AA$, respectively, slightly smaller than the sums of the van der Waals radii (3.70 and $3.82 \AA$, respectively), which give rise to 
Table 1. Crystal data and structure refinement for $\mathrm{Ni}($ dmeds)(dmit).

\begin{tabular}{ll}
\hline Empirical formula & $\mathrm{C}_{14} \mathrm{H}_{12} \mathrm{Ni}_{2} \mathrm{~S}_{10} \mathrm{Se}_{4}$ \\
Formula weight [g/mol] & 934.10 \\
Temperature $[\mathrm{K}]$ & $293(2)$ \\
Wavelength $[\AA]$ & 1.54180 \\
Crystal system, space group & monoclinic, $P \overline{1}$ \\
Unit cell dimensions & \\
$a[\AA$ [ & $6.592(4)$ \\
$b[\AA]$ & $8.236(4)$ \\
$c[\AA]$ & $12.476(7)$ \\
$\alpha[\mathrm{deg}]$ & $87.91(2)$ \\
$\beta[\mathrm{deg}]$ & $75.36(2)$ \\
$\gamma[\mathrm{deg}]$ & $74.49(2)$ \\
$V\left[\AA^{3}\right]$ & $631.1(6)$ \\
$Z$; calculated density $\left[\mathrm{mg} \mathrm{cm}{ }^{-3}\right]$ & $1 ; 2.458$ \\
Absorption coefficient $\left[\mathrm{mm}^{-1}\right]$ & 16.238 \\
$F(000)$ [e] & 448 \\
Crystal size [mm ${ }^{3}$ ] & $0.525 \times 0.150 \times 0.075$ \\
$\theta$ Range for data collection, deg & $5.58-59.00$ \\
Limiting indices & $-6 \leq h \leq 0$, \\
& $-9 \leq k \leq 8$, \\
& $-13 \leq l \leq 13$ \\
Reflections collected/unique & $1981 / 1799\left(R_{\text {int }}=0.039\right)$ \\
Completeness to $\theta=59.03$ & $99.1 \%$ \\
Absorption correction & analytical \\
Max./min. transmission & $0.877 / 0.132$ \\
Data/restraints/parameters & $1799 / 0 / 140$ \\
Goodness-of-fit on $F^{2}$ & 1.068 \\
Final $R$ indices $[I \geq 2 \sigma(I)]$ & $R 1=0.0604, w R 2=0.1615$ \\
$R$ Indices (all data) & $R 1=0.0616, w R 2=0.1646$ \\
Largest diff. peak and hole [e $\left.\AA^{-3}\right]$ & 0.962 and -0.840 \\
\hline &
\end{tabular}

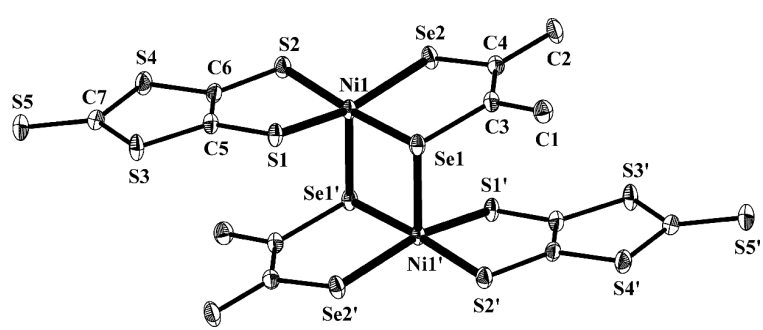

Fig. 1. Molecular structure of $\mathrm{Ni}(\mathrm{dmeds})(\mathrm{dmit})$ with displacement ellipsoids drawn at the $30 \%$ probability level (H-Atoms have been omitted for clarity). Primed atoms are related to unprimed ones by the symmetry operation $1-x$, $-y, 1-z$.

the formation of layers almost parallel to the $a b$ plane (Fig. 2). In other directions the contacts are larger. This indicates a quasi two-dimensional behavior of the material. Single crystals of the other complexes were not good enough for crystal structure determination. However, similar intermolecular interactions ( $\mathrm{S} \cdots \mathrm{Se}$ and $\mathrm{S}$...S contacts) are expected for these complexes.

Conductivity measurements on single crystals of $\mathrm{Ni}$ (dmeds)(dmit) showed an anisotropic behavior, in accordance with the crystallographic results. Fig. 3

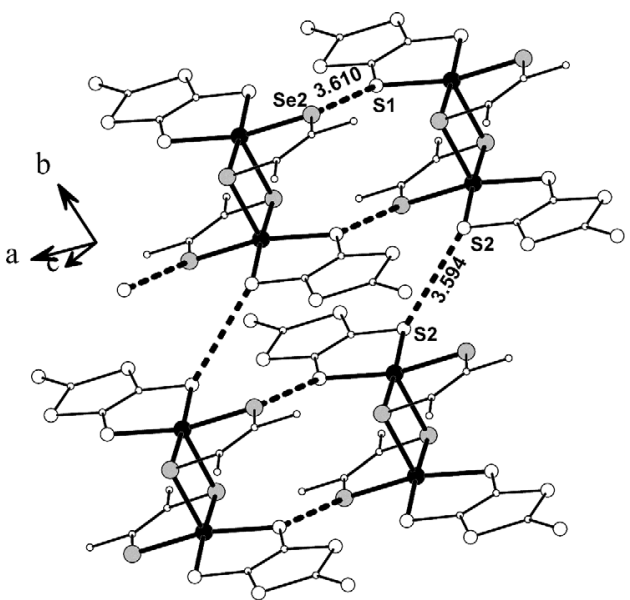

Fig. 2. Partially labeled plot of $\mathrm{Ni}(\mathrm{dmeds})(\mathrm{dmit})$ showing the shortest $\mathrm{S} \cdots \mathrm{S}$ and $\mathrm{Se} \cdots \mathrm{Se}$ intermolecular interactions.

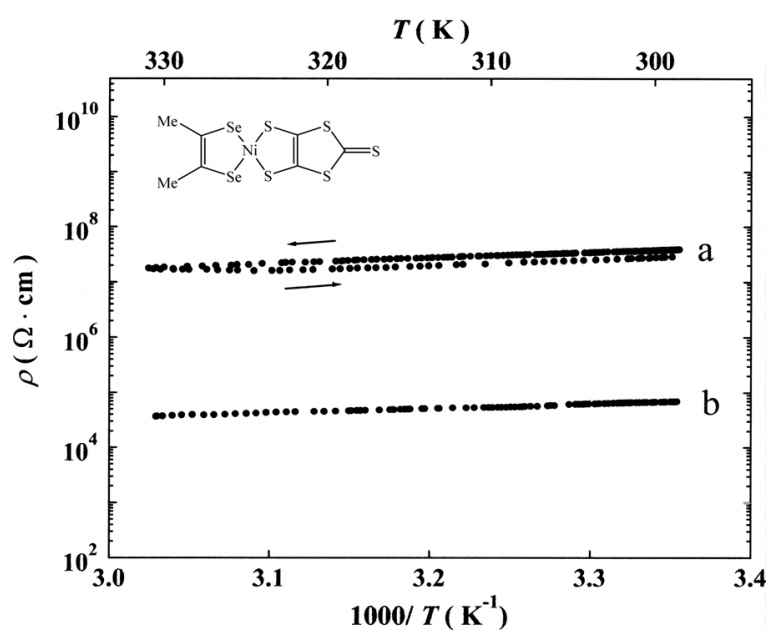

Fig. 3. Plots of resistivity versus the inverse temperature for a single crystal of $\mathrm{Ni}(\mathrm{dmeds})(\mathrm{dmit})$ with currents approximately parallel (a) and perpendicular (b) to the $a b$ plane.

shows the inverse temperature dependence of the resistivity obtained from single crystals of $\mathrm{Ni}$ (dmeds)(dmit) with currents almost parallel to the $a b$ plane $(\|)$ and perpendicular to this plane $(\perp)$. The r.t. conductivity values are $\sigma_{\mathrm{RT}}(\|)=1.5 \times 10^{-5} \mathrm{~S} \mathrm{~cm}^{-1}$ and $\sigma_{\mathrm{RT}}(\perp)=$ $2.5 \times 10^{-8} \mathrm{~S} \mathrm{~cm}^{-1}$. This means that the anisotropy is almost $10^{3}$. The activation energy values were found from the plots of Fig. 3 to be $E_{\alpha}(\|)=0.19 \mathrm{eV}$ and $E_{\alpha}(\perp)=0.18 \mathrm{eV}$. The corresponding band gap $\left(E_{\mathrm{g}}=\right.$ $2 E_{\alpha}$ ) values are 0.38 and $0.36 \mathrm{eV}$. After a series of heating/cooling cycles, the resistance in a number of crystals decreased. Conductivity measurements on compressed pellets of $\mathrm{Ni}(\mathrm{dmeds})(\mathrm{dmit}), \mathrm{Ni}(\mathrm{dmedt})(\mathrm{dmit})$ and $\mathrm{Ni}(\mathrm{dpedt})(\mathrm{dsit})$ gave $\sigma_{\mathrm{RT}}($ pellet $)=1 \times 10^{-6}, 1.2 \times$ 


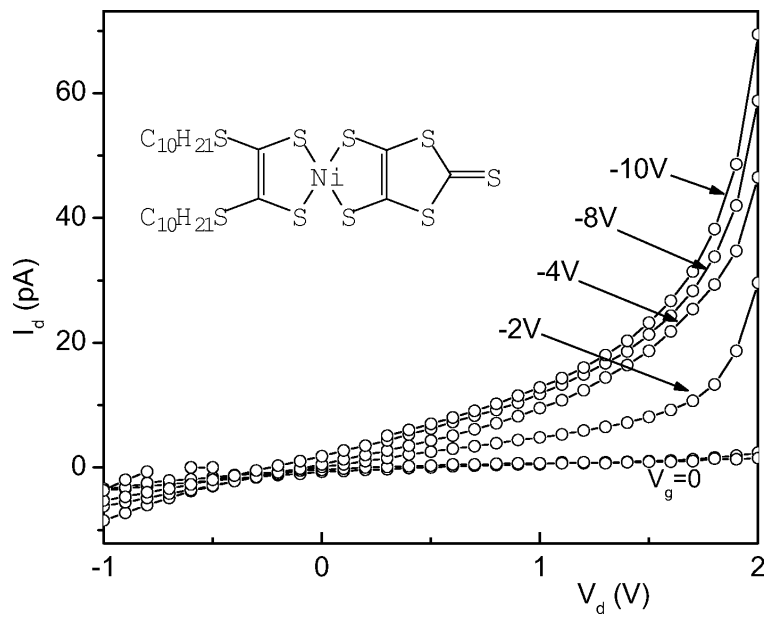

Fig. 4. Plots of $I_{\mathrm{d}} v s$. $V_{\mathrm{d}}$ for several $V_{\mathrm{g}}$ values of a device based on $\mathrm{Ni}(\mathrm{dcdt})(\mathrm{dmit})$

$10^{-7}$, and $1 \times 10^{-7}-5 \times 10^{-6} \mathrm{~S} \mathrm{~cm}^{-1}$, respectively. The $E_{\mathrm{g}}$ (pellet) values were found to be $0.45,0.50-$ 0.80 and $0.46 \mathrm{eV}$, respectively. The $\sigma_{\mathrm{RT}}$ values of $\mathrm{Ni}(\mathrm{dpedt})(\mathrm{dmit})$ and $\mathrm{Ni}(\mathrm{dcdt})(\mathrm{dmit})$ were found to be very small $\left(<10^{-9} \mathrm{~S} \mathrm{~cm}^{-1}\right)$.

The optical absorption (OA) spectra of thin deposits on quartz plates showed strong bands with maxima around $1.24 \mathrm{eV}(1000 \mathrm{~nm})$ and optical band gaps (absorption edges) close to $0.7-0.8 \mathrm{eV}$. This means that, in some complexes, the $E_{\mathrm{g}}$ values obtained from resistivity measurements are smaller than those obtained from the OA spectra of thin deposits (or solutions). This is due to the fact that in compressed pellets and/or single crystals the intermolecular interactions are stronger than those in thin films (or solutions) (see also [5, 6]).

All these air-stable complexes have the electrical and optical features required for candidates for FETs and NLO devices. Preliminary results of measurements under the conditions of FETs were obtained for $\mathrm{Ni}(\mathrm{dcdt})(\mathrm{dmit})$ thin deposits on $\mathrm{Si}_{-} \mathrm{SiO}_{2}$ substrates. Fig. 4 shows the curves of drain current $\left(I_{\mathrm{d}}\right)$ versus the drain voltage $\left(V_{\mathrm{d}}\right)$ for several values of gate voltage $\left(V_{\mathrm{g}}\right)$ of a device based on $\mathrm{Ni}(\mathrm{dcdt})(\mathrm{dmit})$. These curves demonstrate the sensitivity of the channel (semiconductor deposit) to the gate voltage. Several complexes exhibit $p$-type as well as $n$-type conductance. The $I_{\mathrm{d}}-V_{\mathrm{d}}$ curves obtained from $\mathrm{Ni}(\mathrm{dpedt})(\mathrm{dmit})$ were similar to those obtained for $\mathrm{Ni}(\mathrm{dpedt})_{2}$, a material which has been found to exhibit $n$-type conductance [21]. It should be noticed that the best results were obtained for the complexes with the lower values of dc conductivity.
However, more improved techniques are required in order to establish these new materials as semiconductor components of FETs. Also, NLO properties were observed in some of these complexes, which are described separately [5].

\section{Experimental Section}

(Dimethylethylenediselenolato)(1,3-dithiol-2-thione-4,5dithiolato)nickel, Ni(dmeds)(dmit)

In a two-necked $250 \mathrm{~mL}$ flask, a suspension of compounds 1a $(240 \mathrm{mg}, 1 \mathrm{mmol})[11,15]$ and $2(406 \mathrm{mg}$, $1 \mathrm{mmol})[14,17]$ in deoxygenated $\mathrm{MeOH}(10 \mathrm{~mL})$ was prepared. Then, a solution of $\mathrm{NaOMe}$, freshly prepared from $\mathrm{Na}(115 \mathrm{mg}, 5 \mathrm{mmol})$ and $\mathrm{MeOH}(10 \mathrm{~mL})$, was added under nitrogen atmosphere and the mixture stirred for $30 \mathrm{~min}$. To the obtained red solution, a solution of $\mathrm{NiCl}_{2} \cdot 6 \mathrm{H}_{2} \mathrm{O}$ $(238 \mathrm{mg}, 1 \mathrm{mmol})$ in deoxygenated $\mathrm{MeOH}(30 \mathrm{~mL})$ was added dropwise within $15 \mathrm{~min}$. The solution was stirred under nitrogen atmosphere for $1 \mathrm{~h}$ at r.t., whereupon the color turned brown. Then, aq. $\mathrm{HCl}(2 \mathrm{~mL}, 35 \%)$ was added and the mixture was transferred to a beaker and stirred in air overnight. The precipitate was washed with water and $\mathrm{MeOH}$ and dried in air. The green-brown solid was extracted with $\mathrm{CS}_{2}$ and chromatographed on silica gel, using $\mathrm{CS}_{2}$ as eluent. The second green fraction contained $\mathrm{Ni}(\mathrm{dmeds})(\mathrm{dmit})(4 \mathrm{mg}$, $0.9 \%)$. M. p. $>285^{\circ} \mathrm{C}$ (dec.). $-\mathrm{UV} / \mathrm{vis} /$ near IR $\left(\mathrm{CS}_{2}\right): \lambda_{\max }$ $\left(\lg \varepsilon_{\max }\right)=950 \mathrm{~nm}(4.48) .-\mathrm{IR}(\mathrm{KBr}): v=1056,1073(\mathrm{C}=\mathrm{S})$, $2923\left(\mathrm{CH}_{3}\right) \mathrm{cm}^{-1} .-\mathrm{C}_{7} \mathrm{H}_{6} \mathrm{~S}_{5} \mathrm{Se}_{2} \mathrm{Ni}$ (467.03): calcd. C 18.00, H 1.28; found C 18.11, H 1.36.

\section{(Dimethylethylenedithiolato)(1,3-dithiol-2-thione-4,5- dithiolato)nickel, Ni(dmedt)(dmit)}

Using $\mathbf{1 b}(162 \mathrm{mg}, 1 \mathrm{mmol})[12,13,15]$, instead of $\mathbf{1 a}$, and $2(406 \mathrm{mg}, 1 \mathrm{mmol})$, the complex $\mathrm{Ni}(\mathrm{dmedt})(\mathrm{dmit})$ was obtained by the same procedure ( $9 \mathrm{mg}, 2.4 \%)$. M. p. $235^{\circ} \mathrm{C}$ (dec.). - UV/vis/near IR $\left(\mathrm{CS}_{2}\right): \lambda_{\max }\left(\lg \varepsilon_{\max }\right)=933 \mathrm{~nm}$ (4.46). $-\mathrm{IR}(\mathrm{KBr}): v=1048,1064(\mathrm{C}=\mathrm{S}), 2920\left(\mathrm{CH}_{3}\right) \mathrm{cm}^{-1}$. $-\mathrm{C}_{7} \mathrm{H}_{6} \mathrm{~S}_{5} \mathrm{Ni}$ (373.25): calcd. C 22.52, H 1.61; found C 22.48, $\mathrm{H} 1.56$.

\section{(Diphenylethylenedithiolato)(1,3-dithiol-2-thione-4,5- diselenolato)nickel, Ni(dpedt)(dsit)}

Using 3 (270 mg, $1 \mathrm{mmol})$ [13], instead of 1a, and 4 (500 $\mathrm{mg}, 1 \mathrm{mmol})[14,16]$, instead of 2 , the complex $\mathrm{Ni}$ (dpedt)(dsit) was obtained by the same procedure $(15 \mathrm{mg}$, $2.5 \%)$. M. p. $280{ }^{\circ} \mathrm{C}$ (dec.). - UV/vis/near IR $\left(\mathrm{CS}_{2}\right): \lambda_{\max }$ $\left(\lg \varepsilon_{\max }\right)=1005 \mathrm{~nm}(4.52) .-\mathrm{IR}(\mathrm{KBr}): v=1039,1048$ $(\mathrm{C}=\mathrm{S}) \mathrm{cm}^{-1}$. - $\mathrm{C}_{17} \mathrm{H}_{10} \mathrm{~S}_{5} \mathrm{Se}_{2} \mathrm{Ni}$ (591.13): calcd. C 34.54, $\mathrm{H}$ 1.69; found C 34.37, H 1.78. 
(Diphenylethylenedithiolato)(1,3-dithiol-2-thione-4,5dithiolato)nickel, $\mathrm{Ni}($ dpedt)(dmit)

Using 3 (270 mg, $1 \mathrm{mmol}$ ) [13], instead of 1a, and $\mathbf{2}$ (406 $\mathrm{mg}, 1 \mathrm{mmol}$ ), the complex $\mathrm{Ni}(\mathrm{dpedt})(\mathrm{dmit})$ was obtained by the same procedure (104 mg, 21\%). M.p. $240{ }^{\circ} \mathrm{C}$ (dec.). - UV/vis/near IR $\left(\mathrm{CS}_{2}\right): \lambda_{\max }\left(\lg \varepsilon_{\max }\right)=$ $974 \mathrm{~nm}$ (4.65). - IR (KBr): $v=1066,1077(\mathrm{C}=\mathrm{S}) \mathrm{cm}^{-1}$. $-\mathrm{C}_{17} \mathrm{H}_{10} \mathrm{~S}_{7} \mathrm{Ni}$ (497.35): calcd. C 41.05, H 2.01; found C 40.92, H 1.93 .

\section{(1,2-Bis-decylsulfanyl-ethene-1,2-dithiolato)(1,3-dithiol-2- thione-4,5-dithiolato)nickel, Ni(dcdt)(dmit)}

Using 5 (462 mg, $1 \mathrm{mmol}$ ) [14], instead of 1a, and 2 (406 mg, $1 \mathrm{mmol}$ ), the complex $\mathrm{Ni}(\mathrm{dcdt})(\mathrm{dmit})$ was obtained by the same procedure $(5.5 \mathrm{mg}, 0.8 \%)$. M. p. $105{ }^{\circ} \mathrm{C}(\mathrm{dec}$.). - UV/vis/near IR $\left(\mathrm{CS}_{2}\right): \lambda_{\max }\left(\lg \varepsilon_{\max }\right)=1040 \mathrm{~nm}(4.54)$. - IR (KBr): $v=1064,1072(\mathrm{C}=\mathrm{S}), 2915\left(\mathrm{CH}_{3}\right) \mathrm{cm}^{-1}$. $-\mathrm{C}_{25} \mathrm{H}_{42} \mathrm{~S}_{9} \mathrm{Ni}$ (689.57): calcd. C 43.54, H 6.09; found C 43.50, H 6.14.

\section{$X$-Ray crystal structure determination}

A suitable single crystal was mounted in air and diffraction measurements were made on a $P 2_{1}$ Nicolet diffractometer upgraded by Crystal Logic using graphitemonochromated $\mathrm{Cu} K_{\alpha}$ radiation. Crystal data and other numbers pertinent to the structure determination are collected in Table 1. Unit cell dimensions were determined and refined by using the angular settings of 25 automatically centered reflections in the range $22<2 \theta<54^{\circ}$. Intensity data were recorded using $\theta-2 \theta$ scans to $2 \theta_{\max }=118^{\circ}$, with a scan speed of $4.5 \mathrm{deg} \mathrm{min}^{-1}$ and a scan width of $2.45^{\circ}$ plus $\alpha_{1} \alpha_{2}$ separation. Three standard reflections monitored every 97 reflections showed less than $3 \%$ variation and no decay. Lorentz, polarization and analytical absorption corrections were applied using Crystal Logic software. Symmetry equivalent data were averaged with $R_{\text {int }}=0.0389$ to give 1799 independent reflections from a total of 1981 collected. The structure was solved by Direct Methods using SHELXS-86 [22] and refined by full-matrix least-squares techniques on $F^{2}$ with SHELXL-97 [23] using 1799 reflections and refining 140 parameters. All hydrogen atoms were introduced at calculated positions as riding on bonded atoms. All non-hydrogen atoms were refined anisotropically. The largest shift/esd in the final refinement cycle was 0.002 . Table 1 contains further numbers of the structure refinement. CCDC 628860 contains the supplementary crystallographic data for this paper. These data can be obtained free of charge from The Cambridge Crystallographic Data Centre via www.ccdc.cam.ac.uk/data_request/cif.

\section{Physical measurements}

Thin deposits on quartz plates and/or $\mathrm{Si}-\mathrm{SiO}_{2}$ substrates, with predefined interdigitated gold electrodes spaced 2$25 \mu \mathrm{m}$ apart, were obtained by spinning, spraying or drop casting solutions of the complexes in $\mathrm{CS}_{2}$. The OA spectra of the complexes in $\mathrm{CS}_{2}$ or of thin deposits were recorded on a Perkin-Elmer, model Lambda 19 spectrophotometer. The dc conductivity was measured by the well known voltage-drive method. The $I_{\mathrm{d}}-V_{\mathrm{d}}$ characteristics were measured by using a 4140B HP picoammeter.

\section{Acknowledgement}

The work was carried out as a part of the "Excellence in the Research Institutes" project grant 0684, supported by GSRT/Ministry of Development in Greece.
[1] G.C. Papavassiliou, G. A. Mousdis, G.C. Anyfantis, Z. Naturforsch. 2002, 57b, $707-708$.

[2] G. C. Papavassiliou, G. C. Anyfantis, Z. Naturforsch. 2005, 60b, 811-813.

[3] G.C. Anyfantis, G. C. Papavassiliou, A. Terzis, C.P. Raptopoulou, Y.F. Weng, H. Yoshino, K. Murata, Z. Naturforsch. 2006, 61b, 1007-1011.

[4] G. C. Papavassiliou, G. C. Anyfantis, B. R. Steele, A. Terzis, C.P. Raptopoulou, G. Tatakis, G. Chaidogiannos, N. Glezos, Y. F. Weng, H. Yoshino, K. Murata, Abstracts in Proc. of Int. Conf. Synth. Metals (Dublin, 2006), No 023 TU. $I_{\mathrm{d}}-V_{\mathrm{d}}$ characteristies of some unsymmetrical complexes, such as $\mathrm{Ni}$ (pddt)(dmit), $\mathrm{Ni}($ pddt)(dmio) and $\mathrm{Ni}(\mathrm{dpedt})(\mathrm{dmio})$, have been presented.

[5] P. Aloukos, S. Couris, J.B. Koutselas, G. C. Anyfantis, G. C. Papavassiliou, Chem. Phys. Lett. 2006,
$428,109-113$; second hyperpolarizability instead of second-order hyperpolarizability should be corrected therein.

[6] G.C. Anyfantis, G.C. Papavassiliou, P. Aloukos, S. Couris, Y. F. Weng, H. Yoshino, K. Murata, Z. Naturforsch. 2007, 62b, 200-204.

[7] a) J. A. McCleverty, Prog. Inorg. Chem. 1968, 10, 49-221; b) K. Wang in Dithiolene Chemistry (Ed.: E. I. Stiefel), John Wiley, Chichester, 2004, chapter 5, p. 267, and refs. therein.

[8] F. Wudl, E. T. Zellers, S. D. Cox, Inorg. Chem. 1985, 24, $2864-2866$.

[9] G. C. Papavassiliou, A. Terzis, P. Delhaes in Handbook of Organic Conductive Molecules and Polymers, Vol. 1 (Ed.: H. S. Nalwa), John Wiley, Chichester, 1997, chapter 3, p. 151. 
[10] R. Kato, Chem. Rev. 2004, 104, 5319-5346, and refs. therein.

[11] K. Bechgaard, D. O. Cowan, A. N. Bloch, L. Hernisken, J. Org. Chem. 1975, 40, 746-749.

[12] J.P. Ferraris, T. O. Poehler, A. N. Bloch, Tetrahedron Lett. 1973, 2553-2556.

[13] A. K. Bhattacharya, A. G. Hortmann, J. Org. Chem. 1974, 39, 95 - 97.

[14] a) G. C. Papavassiliou, V.C. Kakoussis, D. J. Lagouvardos, G. A. Mousdis, Mol. Cryst. Liq. Cryst. 1990, 181, 171-184; b) G. C. Papavassiliou, V.C. Kakousis, D. J. Lagouvardos, Z. Naturforsch. 1991, 46b, $1269-1271$.

[15] J.-I. Yamada, Resent. Res. Devel. In Org. Chem. 1998, 2, 525-545.

[16] G. C. Papavassiliou, V. C. Kakoussis, J. S. Zambounis, G. A. Mousdis, Chemica Scripta 1989, 29, 123-125.

[17] G. Steimecke, H.-J. Sieler, R. Kirmse, E. Hoyer, Phosphorus, Sulfur Relat. Elem. 1979, 7, 49-55.

[18] a) G. C. Papavassiliou, Z. Naturforsch. 1982, 37b, $825-827$; b) G. C. Papavassiliou, K. Mayer, unpulished work: cyclic voltametric measurements of $\left[\mathrm{Ni}(\mathrm{dmit})_{2}\right]^{-}$in $\mathrm{CH}_{3} \mathrm{CN}\left(0.05 \mathrm{M} \mathrm{Bu}_{4} \mathrm{NPF}_{6}\right)$ and $\mathrm{Pt}$ electrode $v s$. SCE gave $E_{1 / 2}^{1}(2-/ 1-)=-0.180 \mathrm{~V}$, $E_{1 / 2}^{2}(1-/ x-)=0.125 \mathrm{~V}$ and $E_{1 / 2}^{3}(x-/ 0)=0.185-$ $0.235 \mathrm{~V}(0<x<1)$; c) L. Valade, J.-P. Legros, D. deMontauzon, P. Cassoux, L. V. Interrante, Isr. J. Chem. 1986, 27, 353-362.

[19] a) R.-M. Olk, W. Dietzsch, J. Mattush, J. Stach, L. Nieke, E. Hoyer, W. Meiler, R. Robien, Z. Anorg. Allg. Chem. 1987, 544, 199-208; b) R. M. Olk, E. Hoyer, W. Meiler, P. Cassoux, Synth. Met. 1993, 56, 2453-2458; c) P. Cassoux, L. Valade in Inorganic Materials (Eds.: D. W. Bruce, D. O'Hare), John Wiley, Chichester, 1996, chapter 1, p. 3.

[20] S. Alvarez, B. Vicente, R. Hoffmann, J. Am. Chem. Soc. 1985, 107, 6253-6277.

[21] T. Tagushi, H. Wada, T. Kobayashi, B. Noda, M. Goto, T. Mori, K. Ishikawa, H. Takezoe, Chem. Phys. Lett. 2006, 421, 395-398.

[22] G. M. Sheldrick, SHELXS-86, Program for the Solution of Crystal Structures, University of Göttingen, Göttingen (Germany) 1986.

[23] G. M. Sheldrick, SHELXL-97, Program for the Refinement of Crystal Structures, University of Göttingen, Göttingen (Germany) 1997. 